\title{
CONSIDERACIONES SOBRE LA EDICIÓN DE MANUSCRITOS ÁRABES
}

\author{
Luis Molina \\ C.S.I.C., Granada
}

Difícilmente podrá encontrarse un arabista que esté en desacuerdo con el enunciado de que el objetivo que se debe perseguir al editar una obra es el de poner al alcance de los lectores un texto "correcto". Pero, al mismo tiempo, la definición de lo que debemos entender por "correcto" habrá de provocar sin duda discrepancias insalvables, desde los que dan a ese término su sentido más etimológico de "corregido", interpretación que permite al editor modificar todo lo que él considera erróneo en el texto desde cualquier punto de vista, hasta los que opinan que la corrección radica en el respeto escrupuloso a lo que nos han transmitido los manuscritos - o, en su caso, el manuscrito- objeto de la edición. En otros ámbitos de la Filología, en los que se ha producido un mayor desarrollo de la reflexión teórica sobre la Crítica Textual, la cuestión, al menos en sus principios básicos, está resuelta desde hace mucho tiempo: la edición crítica debe dar como resultado un documento lo más cercano posible al original salido de la pluma del autor ${ }^{1}$. El objetivo perseguido es claro, y es en los medios para alcanzarlo donde surgen las discrepancias entre las distintas escuelas. Pero en esas discusiones no vamos a entrar aquí, porque sería perderse en disquisiciones bizantinas; no porque esos debates carezcan de interés - muy al contrario, a pesar de algunos excesos un tanto ridículos-, sino porque en el ámbito del arabismo tales precisiones metodológicas se hallan a tal distancia de las cuestiones que suelen ocupar realmente a los editores de textos árabes clásicos que resultaría casi pedante detenerse en ellas. ¿Para qué discutir sobre cuál es el método más acertado para conocer el documento original, el redactado por el autor, cuando lo que suelen buscar los arabistas es primordialmente la adecuación del texto editado a las normas gramaticales, inmutables e intemporales? ¿Qué sentido tendría plantearse la licitud o los límites de la emendatio ope ingenii si a cada paso nos topamos con editores que no sólo corrigen lo que consideran erróneo, sino que no vacilan en «mejorar» el estilo del autor?

\footnotetext{
${ }^{1}$ Para una visión de conjunto de la Crítica Textual, son útiles los trabajos de Bernabé, A., Manual de crítica textual y edición de textos griegos, Madrid, 1992, y Blecua, A., Manual de crítica textual, Madrid, 1983, así como los artículos publicados en Arbor XCLVIII, 582 (junio 1994). Entre los dedicados específicamente a la edición de textos árabes cabría citar Blachère, R., y Sauvaget, J., Règles pour éditions et traductions de textes arabes, París, 1953; al-Munaŷŷid, S., Reglas para la edición crítica de textos árabes (trad. J. M. Fórneas), Instituto de Manuscritos Árabes, 1958; 'Usaylān, A. A., Tahquīq al-majțütāt: bayna l-wäqi ‘ wa-l-nahŷ al-amtal, Riyad, 1415 h. [1994], todos ellos con una finalidad eminentemente práctica.
} 
Cuando nos encontramos con ediciones pretendidamente científicas que han sido elaboradas únicamente basándose en otras anteriores que son corregidas de acuerdo con los conocimientos gramaticales e históricos del nuevo editor, o leemos reseñas de ediciones en las que se proponen lecturas supuestamente más acertadas sin que el firmante de la crítica haya consultado los manuscritos utilizados, podemos comprobar que las normas más elementales de la Crítica Textual no son moneda de uso corriente en nuestro entorno científico, donde, por el contrario, lo que parece dominar es el afán por demostrar nuestros conocimientos lingüísticos y filológicos o, tal vez, el temor a que alguien nos pueda echar en cara nuestra ignorancia.

Pero en muchas ocasiones la ignorancia no se revela al conservar una lectura aparentemente errónea, sino al efectuar enmiendas no pertinentes. Como señala Alberto Bernabé, «a veces no se trata de que una forma no es correcta, sino que nosotros no sabemos que lo es. O, en ocasiones, el error es producto del autor, y es inútil tratar de corregirlo. El editor debe cuidar de no llevar su tarea hasta corregir al autor que está editando porque le parece que puede escribir mejor en griego o en latín que él»".

Piénsese en que una obra de la magnitud, importancia y, sobre todo, utilidad como el Supplément aux Dictionnaires arabes de Dozy es, en gran medida, un repertorio de voces que presentan variantes, anomalías, usos no documentados, dialectalismos, etc., que un editor purista hubiera corregido sin duda para acomodarlas a la norma - de hecho, todavía nos encontramos con editores que siguen dando por erróneas palabras y expresiones que se hallan perfectamente documentadas en el Supplément, pero que no aparecen reflejadas en los diccionarios "canónicos»-

Buena parte del problema proviene de que los editores de este tipo parten de dos premisas para ellos indiscutibles: los copistas de los manuscritos eran siempre personas incultas, descuidadas y proclives al error, y los lectores a los que se dirige la edición son individuos de débiles conocimientos a los que es preciso proteger presentándoles un texto del que no puedan extraer ninguna enseñanza equivocada.

Es indudable que los copistas no son infalibles y que es difícil que un texto mejore al pasar por las manos de uno de ellos, siendo casi inevitable que en el transcurso de la copia se añadan nuevos errores a los que ya aparecían en el ejemplar utilizado como modelo. Pero no es menos cierto que la mayoría de esos errores pueden ser subsanados fácilmente al tratarse de fallos de lectura o de escritura que suelen dejar una huella evidente y manifiesta: atendiendo a criterios paleográficos es generalmente factible explicar y corregir el error. Sin embargo, hay ocasiones en las que la influencia del copista es mucho más peligrosa: justamente cuando se comporta como uno de esos editores a los que nos estamos refiriendo $\mathrm{y}$, al

2 Bernabé, A., op. cit., p. 88. 
encontrarse con un pasaje supuesta o realmente corrupto, decide arreglarlo por su cuenta y riesgo, dando como resultado un texto comprensible y que no llama en modo alguno la atención del lector, pero que en el fondo no deja de ser lisa y llanamente una falsificación indetectable a simple vista (y no siempre vamos a disponer de otros códices escritos por copistas más escrupulosos que nos permitan descubrir esa intervención).

En cuanto a la voluntad de hacer accesible al lector el texto que se edita, facilitándole la comprensión y corrigiendo los errores de todo tipo (ortográficos, sintácticos, lexicográficos, históricos) que en él se contienen, es comprensible que en el ámbito arabófono se publiquen ediciones de divulgación, con el mismo espíritu que impregnaba la en otros tiempos famosa colección de clásicos castellanos "Odres nuevos". Pero no por ello debemos olvidar que una edición científica y crítica es algo totalmente distinto, y que sus destinatarios son personas a las que se les presupone la formación y los conocimientos suficientes para distinguir lo correcto de lo erróneo, lo verdadero de lo falso, para saber, en definitiva, que el texto que tienen entre sus manos no tiene por qué ser un modelo desde el punto de vista gramatical o estilístico y que los datos en él contenidos pueden ser equivocados o inciertos.

Una obra literaria refleja los conocimientos, las ideas e incluso los sentimientos de su autor; por deficientes que fueran sus conocimientos, insostenibles sus ideas y perversos sus sentimientos, no es en modo alguno función del editor rectificar las palabras del autor, sino que su misión debe ser la de transmitirlas lo más fielmente posible, sin permitirse más intervenciones que las estrictamente imprescindibles, siempre regidas por el más profundo respeto hacia el texto recibido, del que no es autor, responsable ni depositario, sino mero transmisor.

El objetivo de toda edición científica, por tanto, está —o debería estar- muy claro, pero, puesto que en la mayoría de las ocasiones no disponemos de un manuscrito autógrafo del autor y tenemos que servirnos de copias posteriores cuya fidelidad al original desconocemos en principio, obviamente será preciso recurrir a una serie de técnicas y métodos que nos permitan identificar los pasajes que han sufrido modificaciones en relación a la versión salida de la pluma del autor y restituirlos a su redacción original. De dichas técnicas y métodos se ocupa la Crítica Textual, tan poco conocida y aún menos utilizada entre los arabistas. Las páginas siguientes las dedicaremos a comentar algunos aspectos de la Crítica Textual aplicada a la edición de textos árabes, sin pretender con dichos comentarios ni fijar unas normas indiscutibles y universales ni mucho menos redactar un manual para arabistas.

La labor de edición de un texto se divide tradicionalmente en dos fases principales: la recopilación, análisis y clasificación de los testimonios, tanto directos (los propios manuscritos que contienen la obra en cuestión) como 
indirectos (citas en otras fuentes), fase que suele ser denominada recensio, y la elaboración de un texto a partir de dichos testimonios, la constitutio textus.

Sobre la primera de estas fases no nos detendremos mucho, ya que se trata de una labor casi mecánica, en la que la aportación personal del editor debe reducirse al mínimo. En efecto, lo que se persigue en el proceso de la recensio es preparar convenientemente el material documental que en el siguiente paso nos servirá para fijar el texto. En esta preparación se incluye la transcripción de los manuscritos, transcripción que debe ser estrictamente paleográfica, el acopio de testimonios indirectos por medio de la búsqueda de citas, expresas o no, en otras obras, la localización de lecturas divergentes en los distintos códices y, finalmente, la elaboración del stemma, el cuadro de filiación de los distintos manuscritos, que es en lo que el editor debe basarse a la hora de elegir cuál de las distintas lecturas que presentan es la correcta. Obviamente, la constitución del stemma no tiene sentido cuando se dispone de un único manuscrito e incluso cuando se cuenta con dos, ya que, en este caso, lo único a discernir es si ambos derivan independientemente de un modelo común o uno de ellos es modelo del otro.

De todo este proceso, lo único que nos interesa subrayar es que la valoración de las variantes que hallamos en los distintos códices — con vistas a la elección de la más apropiada a la hora de fijar el texto- no puede basarse, como es habitual en el arabismo, en la mayor o menor "corrección" desde el punto de vista gramatical, histórico, científico, etc. Teniendo en cuenta que lo que perseguimos es la restitución de la versión original del autor, si del stemma se desprende que un manuscrito A deriva de uno B y, por tanto, éste se encuentra más cercano al original que aquél, la variante aparentemente más correcta que hallamos en A sólo pude ser debida a que su copista enmendó por su cuenta, al considerarla errónea, la lectura que encontró en su modelo. Con independencia del grado de acierto del copista al efectuar esa rectificación, lo cierto es que la lectura de A no puede ser considerada estrictamente un testimonio, sino una emendatio ope ingenii, es decir, más una opinión que un dato. Lo mismo podríamos decir del recurso a la lectio plurimum codicum, la adopción de la variante que aparece en un mayor número de manuscritos, circunstancia que puede deberse simplemente al hecho de que se nos hayan conservado más representantes de una familia de manuscritos, todos ellos derivados de un modelo único, cuyo testimonio, en principio, no tiene por qué ser preferible al de otros códices.

Como resultado de la labor de recensio, contamos con unos testimonios que nos van a permitir fijar una primera versión del texto, versión elaborada exclusivamente con el material proporcionado por dichos testimonios. En otras palabras, el texto obtenido es un transcripción exacta del manuscrito - en el caso de un unicum - o el resultante de seleccionar las variantes cuando nos ha llegado más de uno; pero, en uno y otro caso, todas las palabras del texto se hallan documentadas en algún testimonio. Lógicamente, el siguiente paso sería mejorar las imperfecciones que inevitablemente presenta dicho texto, pero en este momento habría que plantearse 
una serie de preguntas: ¿se debe modificar el textus receptus?, ¿puede hacerse con garantías? Y, en caso de respuesta afirmativa a ambas cuestiones: ¿cómo y con qué criterios?

En este punto, y antes de responder a tales preguntas, conviene hacer dos consideraciones:

Si tenemos en cuenta que el objetivo que se persigue es el de reproducir lo más fielmente posible las palabras exactas del autor y que esas palabras podían estar plagadas de errores de todo tipo, la restitución de ese original sólo puede apoyarse en los testimonios escritos que efectivamente se nos han conservado, y no en la adecuación del léxico, la sintaxis y el contenido a unas normas y a unos conocimientos que el autor, voluntaria o involuntariamente, pudo dejar de lado.

Al mismo tiempo, es totalmente inevitable que en el proceso de copia de un códice, el escribano cometa errores de lectura o escritura. Por lo tanto, cualquier manuscrito al que nos enfrentemos, salvo que sea autógrafo, contendrá con toda seguridad erratas achacables al copista.

Ante esto, la respuesta a las preguntas que nos formulábamos antes está clara: hay que corregir el texto para librarlo de las erratas de los copistas, peîo respetando los posibles errores del autor. La dificultad radica, claro está, en el hecho de que muchas veces es imposible determinar si un pasaje que nos parece corrupto o equivocado lo es por negligencia en el proceso de copia o se hallaba así en la redacción original. De este modo, la cuestión sigue planteada en los mismos términos que antes: ¿puede el editor recurrir a la emendatio ope ingenii para modificar el textus receptus? Y, si se responde afirmativamente, ¿cuándo y cómo?

Pero antes de entrar finalmente en la discusión sobre la licitud y los métodos de la corrección conjetural, permitásenos una breve incursión en un aspecto al que sólo nos hemos referido anteriormente de pasada: la utilización de testimonios indirectos, es decir, de fuentes que reproducen más o menos literalmente pasajes del texto que se edita. Es bien sabido que en la civilización árabe clásica, la utilización de textos de otros autores de forma sistemática e intensiva es una práctica frecuente, aceptada e incluso prestigiosa. Gracias a ello, las citas que de una obra encontramos en autores más tardíos suelen ser numerosas y, lo que es más importante, muy fieles a su modelo, de modo que esta práctica pone a nuestra disposición un material documental utilísimo para corregir y completar el texto proporcionado por los testimonios directos. Sin embargo, es preciso obrar con precaución al emplear el material de este tipo: si antes comentábamos el riesgo que supone el que un copista, al encontrarse con una pasaje obscuro, lo aclare y mejore, ese peligro se acrecienta cuando se trata de un autor, responsable por tanto de lo que escribe, aunque esté citando, que obviamente procurará evitar todo lo que a sus ojos parezca como una incorrección de su fuente. Añadamos a esto que, por muy fiel a su modelo que pretenda ser, siempre podrá introducir a sabiendas o por descuido modificaciones que alteren el texto original, siquiera sea 
mínimamente. Por ello, los testimonios indirectos nunca deben ser colocados al mismo nivel que los directos, sino que han de ser utilizados a la hora de la fijación del texto como documentación auxiliar; por lo general, las lecturas de estas fuentes paralelas deben ser confinadas en el aparato crítico, incluso cuando nos ofrecen pasajes que rellenen lagunas del original. La inclusión de lecturas de fuentes paralelas en el texto editado se producirá únicamente en los casos y bajo las condiciones que a continuación comentaremos al referirnos a las conjeturas.

Pasemos, por tanto, a analizar las condiciones que deben darse para que el editor pueda y deba intervenir en el texto atendiendo únicamente a su criterio y a sus conocimientos, sin base documental, lo que en Crítica Textual es conocido por emendatio ope ingenii o conjetura. Vaya por delante, y posiblemente sea ocioso mencionarlo, que no entra dentro de este punto la modernización de la grafía: vacilaciones alif-alif maqșūra, scriptio plena o defectiva, soporte de hamza, etc., modificaciones que el editor debe introducir sin indicarlo en nota, para evitar recargar excesivamente el aparato crítico, si bien no está de más describir con brevedad y de modo general esas peculiaridades al estudiar las características paleográficas de los manuscritos en la introducción a la edición.

El peso de la prueba recae sobre el editor. El editor, antes de proponer una conjetura, debe presentar argumentos convincentes que demuestren la existencia de error indudable en el pasaje que pretende corregir. La conjetura debe ser, por lo tanto, respuesta a un pasaje obscuro o corrupto, nunca un intento de mejorar el texto.

La corrección propuesta debe ser plausible desde el punto de vista paleográfico; dicho de otro modo, la transformación del texto original -que supuestamente es el que se restituye con la conjetura- en el consignado por el copista debe ser explicable de forma sencilla y lógica.

Las posibles particularidades del lenguaje del autor, incluyendo dialectalismos, barbarismos y, ¿por qué no?, incorrecciones derivadas de un deficiente conocimiento del árabe, deben ser conservadas en el texto editado. Cualquier aclaración que el editor desea hacer constar debe aparecer en nota.

Por muy respetuoso con el textus receptus que se intente ser - postura, por otra parte, muy elogiable - , hay dos casos en los que la intervención del editor es imprescindible: la presencia de consonantes sin puntos diacríticos y las repeticiones indebidas de palabras o frases, muy frecuente en los cambios de página (la aparición de un error de este tipo en medio de una página en ocasiones indica que en ese punto se producía un cambio de página en el códice copiado; dato que, a veces, puede ser significativo). En cuanto a las consonantes no puntuadas, es evidente que no se puede publicar un texto ilegible, por lo que el editor debe restituir la puntuación, labor que en la inmensa mayoría de los casos será muy sencilla. 
Para concluir con la emendatio ope ingenii, no estará de más reproducir un párrafo de Alberto Blecua sobre esta cuestión. Creemos que es el mejor colofón a todo lo que acabamos de exponer aquí.

La emendatio ope ingenii sin ayuda de testimonios, y aun con ellos - una emendatio mixta-, es siempre peligrosa y se debe prodigar lo menos posible. La conjetura es un "salto en el vacío", que sólo la aparición de nuevos testimonios puede servir de piedra de toque. Al parecer, el número de conjeturas atinadas —en el campo de la filología clásica - no supera el 5 por 100. Porcentaje poco elevado, desde luego. La conjetura, sin embargo, es recomendable siempre que exista un locus criticus oscuro, porque de este modo se llama la atención sobre él y permite un diálogo -o un debate- filológico que enriquece el conocimiento del texto. Pero es preferible relegar la conjetura al aparato de variantes si los argumentos no son definitivos - que rara vez llegan a serlo. Y sobre todo, antes de llevar a cabo una conjetura deben agortarse todas las posibilidades de explicar ese locus obscurus, que puede no ser oscuro por error de copia, sino por deficiencias de nuestro conocimiento filológico. En la emendatio ope ingenii, en resumen, la prudencia máxima ${ }^{3}$.

\section{EL FUTURO DE LA EDICIÓN DE TEXTOS}

En las páginas anteriores hemos venido exponiendo nuestras opiniones sobre cómo debe elaborarse una edición crítica de un texto árabe. Pues bien, éste es el momento de reconocer que, en realidad, no consideramos que el método expuesto sea el mejor, el más eficaz o el más riguroso, es simplemente el más apropiado de entre los que se emplean habitualmente. Pero esto ha de cambiar muy pronto.

$\mathrm{El}$ inconveniente que presenta este método - y todos los tradicionales- es que obliga, en todas y cada una de las fases del proceso, a elegir entre una serie de posibilidades, optando por una y abandonando las demás: el resultado del trabajo de edición, tal y como lo conocemos en la actualidad, es un texto impreso, único y fijo que, por mucho que se complemente, matice y explique con un extenso aparato crítico, deja al margen -más exactamente, a pie de página - un enorme caudal de variantes desechadas, opciones descartadas, hipótesis inseguras. El texto editado tal vez sea el mejor de los posibles, pero desde luego, ni es el único posible ni por lo general es un texto realmente existente, sino una recreación ideal.

Por otra parte, cualquier manuscrito contiene una información no textual (colores, signos, adornos), difíciles de reproducir o incluso de señalar en una edición impresa y que pueden tener cierto valor. Un caso que nos afecta en especial, aunque no exclusivamente, a los arabistas es el de la vocalización:

${ }^{3}$ Blecua, A., op. cit., p. 125-126. 
muchos manuscritos están total o parcialmente vocalizados, pero, por diversos motivos, no se considera aceptable reproducir toda la vocalización en un texto editado. En el mejor de los casos, cuando los condicionamientos tipográficos lo permiten, se suelen incluir las vocales en pasajes oscuros y en los topónimos y antropónimos menos conocidos ${ }^{4}$, pero, en última instancia, lo cierto es que una información que aparece en el manuscrito se pierde en su paso a la imprenta.

Es evidente que todos estos problemas son de imposible solución si se utiliza la publicación impresa como vehículo de difusión; reproducir de forma paralela e íntegra las distintas versiones de una obra ${ }^{5}$ es una solución cara, compleja, insufrible para el lector y sobre todo, incompleta, pues no da respuesta a muchos de los problemas a los que hemos aludido. No, lo cierto es que esta limitación, hasta ahora no sentida como tal, sólo puede ser superada por medio de la utilización del soporte informático en lugar del papel — siendo realistas, habría que decir: además del papel. Es la solución más sencilla, económica y razonable, si bien tiene algo en su contra: ni los editores ni los lectores parecen disponer de los medios materiales y de los conocimientos técnicos necesarios para que una publicación electrónica sea factible y goce de una mínima difusión. Las indudables ventajas que representa el hecho de utilizar un texto en formato electrónico (localización instantánea de cualquier término y posibilidad de copiar e incluir en otro documento citas sin necesidad de mecanografiarlas, por poner un par de ejemplos) no han logrado vencer la fuerza de la tradición hasta ahora, pero es indudable que en un futuro muy próximo el ámbito del arabismo estará preparado para aprovechar las posibilidades de la informática.

La edición electrónica que aquí propugnamos no es única ni principalmente un mero cambio de soporte físico, pasando del papel al disco o al CD-ROM. Las diferencias son mucho más profundas y afectan tanto al contenido como a la presentación, pues en realidad lo que se publica no es el resultado final del proceso de edición, el texto fijado y establecido por el editor, sino todas las fases del proceso, desde el manuscrito hasta las conjeturas más arriesgadas.

En efecto, la edición electrónica se configura como un texto en capas, la primera de las cuales es el manuscrito digitalizado (los manuscritos, si son más de uno), es decir, una colección de archivos de imágenes cada uno de los cuales contiene la reproducción de una página del manuscrito. Estas imágenes van vinculadas a un archivo de texto en el que se almacena una transcripción paleográfica que debe respetar totalmente la grafía del original (así como otras características a las que antes nos referíamos como colores, símbolos, reclamos,

4 No está de más mencionar que la vocalización que se incluya en una edición debe estar documentada en los manuscritos. Si el editor considera que un pasaje puede ser aclarado añadiendo por su cuenta la vocalización de ciertas palabras, la nota a pie de página es un lugar idóneo para ello.

${ }^{5}$ Es una experiencia que ha sido puesta en práctica en casos muy concretos; véase De Casas, F.; Del Prado, J.; y Sanz, A., "La edición crítica de textos franceses", Arbor XCLVIII, 582 (junio 1994), p. 111. 
etc). La vinculación entre las imágenes y el texto tiene como finalidad el que se puedan realizar búsquedas de palabras en el documento y que, si así se desea, lo que aparezca en pantalla sea la imagen correspondiente a la página del manuscrito en la que se ha localizado el término buscado.

La segunda capa de edición estaría formada por la transcripción literal del texto de cada uno de los códices, pero con la grafía adaptada a los usos modernos y con las correcciones mínimas e imprescindibles (restitución de puntos diacríticos omitidos, supresión de repeticiones, puntuación y división en párrafos). Por último, la tercera capa sería la equivalente a lo que, en el caso de una edición impresa, sería el texto fijado, reuniendo, de acuerdo con los métodos ya comentados anteriormente, todos los testimonios disponibles para elaborar la edición crítica. A partir de ahí, el editor podrá añadir tantas capas como desee, reconstruyendo con ayuda de fuentes paralelas pasajes perdidos, proponiendo lecturas más correctas, añadiendo, suprimiendo y modificando, en definitiva, todo lo que estime oportuno. En contrapartida, el lector podrá elegir la capa que le interese, de forma que será libre de aceptar o no las opiniones y conjeturas del editor. Al mismo tiempo, estará en condiciones de crear su propia capa de edición, añadir las anotaciones que juzgue pertinentes, copiar parte del texto para introducirlo en un documento propio $\mathrm{y}$, obviamente, imprimir en nuestro viejo y querido papel cualquier parte de la edición electrónica, ya sea texto o imágenes del manuscrito.

A las distintas capas de edición se puede acceder por dos medios: bien de forma independiente, seleccionando la capa que se desee directamente, bien partiendo desde una capa determinada y marcando una palabra o frase que presente diferencias entre unas capas y otras; al marcar ese pasaje aparecerá una relación de las variantes que ofrece y, desde esa relación, se podrá acceder a la capa en la que se incluya la variante elegida, así como a cualquier explicación por parte del editor que aclare el pasaje en cuestión o explique las razones de las modificaciones por él introducidas.

Finalmente, este sistema permite también la incorporación al texto de la vocalización existente en los manuscritos, vocalización que, a voluntad del lector, puede ser ocultada a la vista.

Si reflexionamos con detenimiento sobre todo esto, veremos que tiene unas implicaciones que van más allá de lo puramente práctico. En realidad, este sistema de edición modifica muy sensiblemente el papel del editor científico que, por un lado, gana en libertad de actuación al saber que las conjeturas que plantee son, en cierto modo, menos definitivas $\mathrm{y}$, permítasenos la expresión, menos comprometedoras que si las incluyera en el texto único e inmutable de una edición impresa. Pero, al mismo tiempo, el editor electrónico pierde ese carácter casi de coautor que tiene ahora para pasar a ser un simple exégeta cuyas opiniones y comentarios pueden tener mayor o menor valor, según su prestigio, pero ya no forman parte indisoluble del texto editado. Tal vez nos equivoquemos, pero 
tenemos la impresión de que, en una edición electrónica como la que hemos descrito, los lectores recurrirán por regla general más a una de las dos primeras capas de edición - la transcripción facsimilar y la transcripción corregida- que a las que son realmente ediciones. Posiblemente en esta circunstancia hallemos los más fuertes obstáculos a la generalización de la edición electrónica: aceptar todo esto supone un ejercicio de humildad que a muchos se les antojará excesivo.

\title{
RESUMEN
}

El objetivo que debe perseguir el editor de un texto árabe es el de acercarse lo más posible al original salido de la pluma del autor, respetando incluso sus posibles errores. En este artículo se presenta también una breve reflexión sobre la utilización de las técnicas informáticas para la edición de textos árabes.

\begin{abstract}
The objective which the editor of an Arabic text ought to pursue is to approach as nearly as possible to the original produced by the author's pen, respecting as well possible errors. This article presents as well a brief reflection on computer methods for editing Arabic texts.
\end{abstract}

